\title{
First Ron Hites Award goes to Alison E. Ashcroft, Sheena Radford, and Coauthors
}

W

e are pleased to announce the first Ron Hites Award to Alison E. Ashcroft, Sheena Radford, and their coauthors for their paper, "Monitoring Co-populated Conformational States during Protein Folding Events Using Electrospray Ionization-Ion Mobility Spectrometry-Mass Spectrometry" by David P. Smith, Kevin Giles, Robert H. Bateman, Sheena E. Radford, and Alison E. Ashcroft, J. Am. Soc. Mass Spectrom., 2007, 18, 2180-2190.

"The Ron Hites Award recognizes a high quality presentation of outstanding original research. Selection is based on a paper's innovative aspects, technical quality, likely stimulation of future research, likely impact on future applications, and quality of presentation. The Award is named in honor of Professor Ronald A. Hites of Indiana University, who led the creation of JASMS in 1988 while president of ASMS." (from the 2009 ASMS Conference Program). The award was announced in an editorial by ASMS president, Gary Glish, JASMS, November 2008, 19, 1577.

Alison Ashcroft is Professor of Biomolecular Mass Spectrometry in the Astbury Centre for Structural Molecular Biology and the Faculty of Biological Sciences at the University of Leeds, UK. After post-doctoral research at the University of Geneva, Switzerland, Ashcroft went into industry (Kratos Analytical, AstraZeneca, Micromass/Waters) before joining the University of Leeds in 1997. Her research is focused on the application and development of mass spectrometry for studying protein folding and protein conformer characterization, biomolecular assembly pathways, and protein structural elucidation. She is interested in ion mobility spectrometry coupled to mass spectrometry to separate co-populated protein species in real-time and to characterize tertiary and quaternary protein structure. She was appointed President of the British Mass Spectrometry Society (BMSS) in 2008 and is a past BMSS Chair and past Secretary of the International MS Foundation.

Sheena Radford is Professor of Structural Molecular Biology in the Astbury Centre for Structural Molecular Biology at the University of Leeds. After post-doctoral research at the Oxford Centre for Molecular Sciences, University of Oxford, UK, she moved to the University of Leeds in 1995, where she continued to develop her interests in protein folding and the role of misfolding in amyloid disease by using an array of methods, including NMR and mass spectrometry. Radford was awarded the

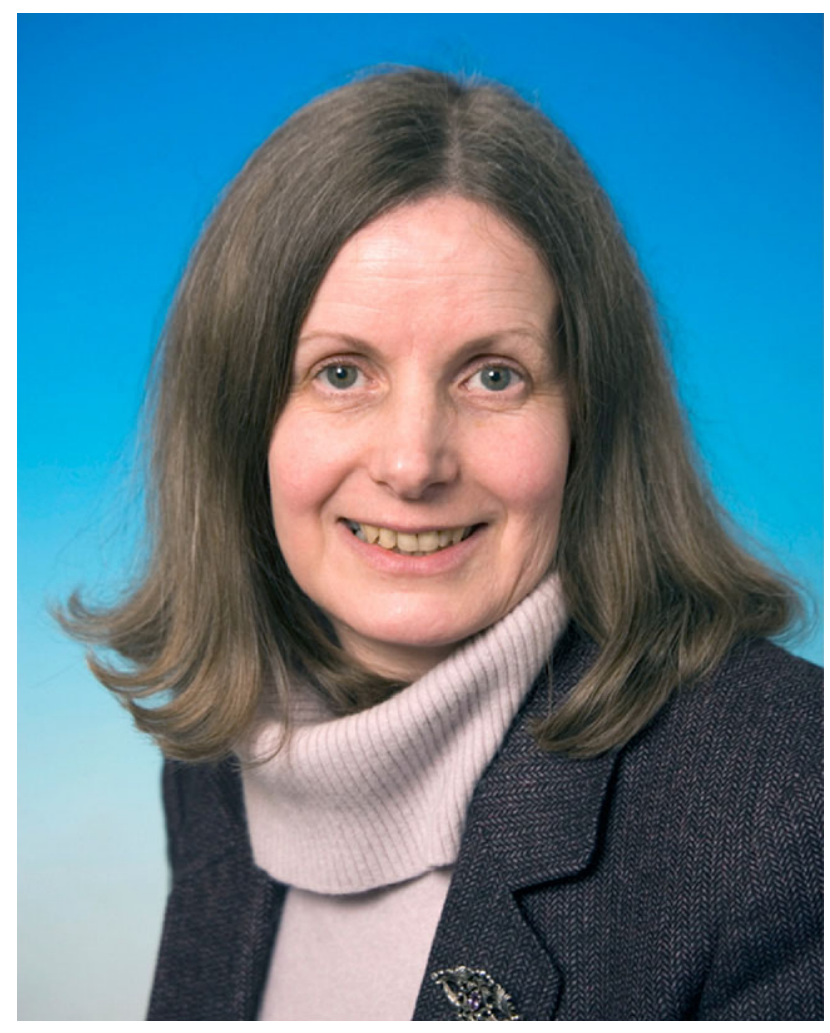

Colworth Medal and the Astra-Zeneca prize for Protein and Peptide Research and was elected a member of EMBO.

David Smith is a post-doctoral research fellow in the Ashcroft and Radford research groups. After completion of his Ph.D. in 2003 at the University of Leeds, Smith spent two years at the University of Melbourne, studying the role of metal ions and amyloid- $\beta$ in the pathology of Alzheimer's disease before returning to Leeds to continue research into amyloid fibril formation by using mass spectrometric techniques.

Kevin Giles joined VG Biotech in 1992, after postdoctoral research in ion mobility and mass spectrometry at Montana State University, and was involved in the development of quadrupole-based mass spectrometers. Between 1995 and 1998, he worked at the UK's Chemical and Biological Defense Establishment, undertaking research into ion mobility and mass spectrometry for chemical and biological agent detection. He joined Waters/Micromass in 1998 and has been involved 


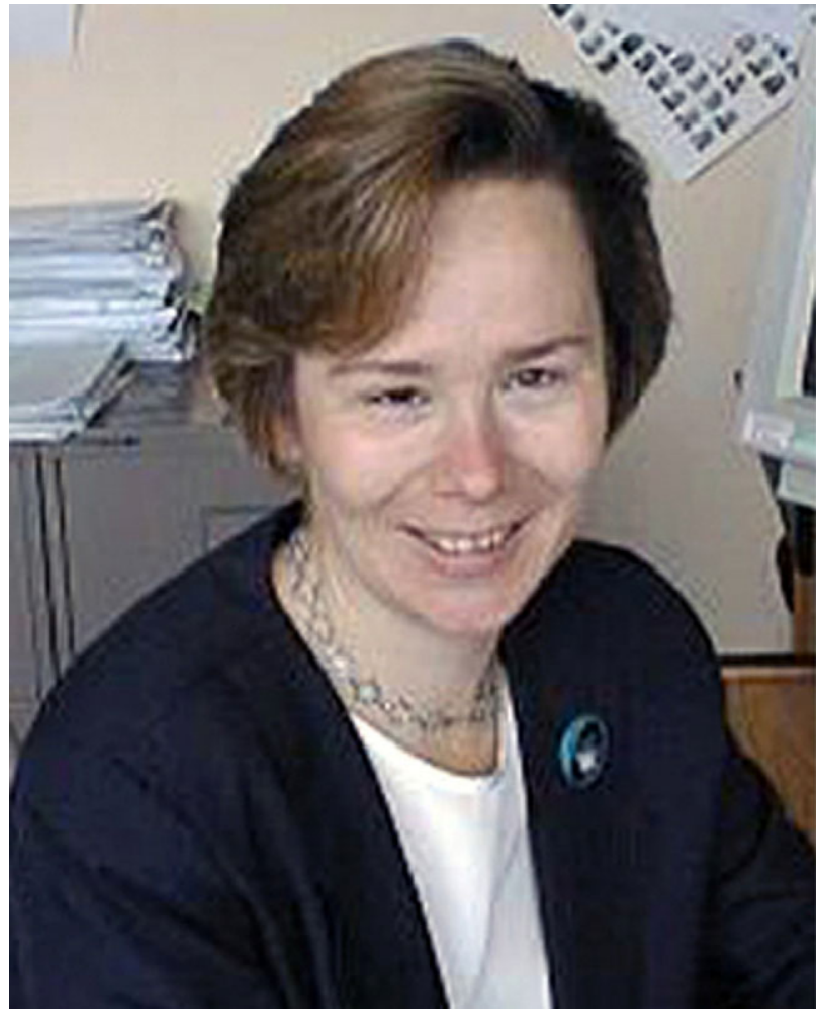

in the development of single and tandem quadrupole mass spectrometry systems and hybrid quadrupole/Tof instrumentation.

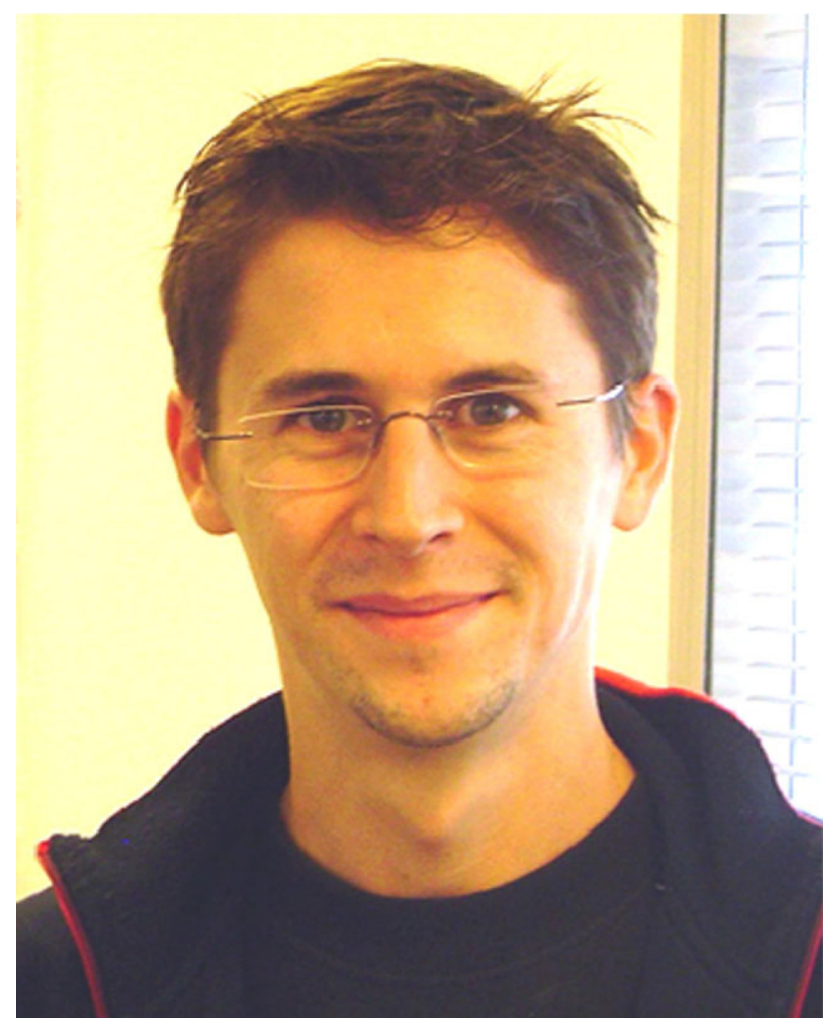

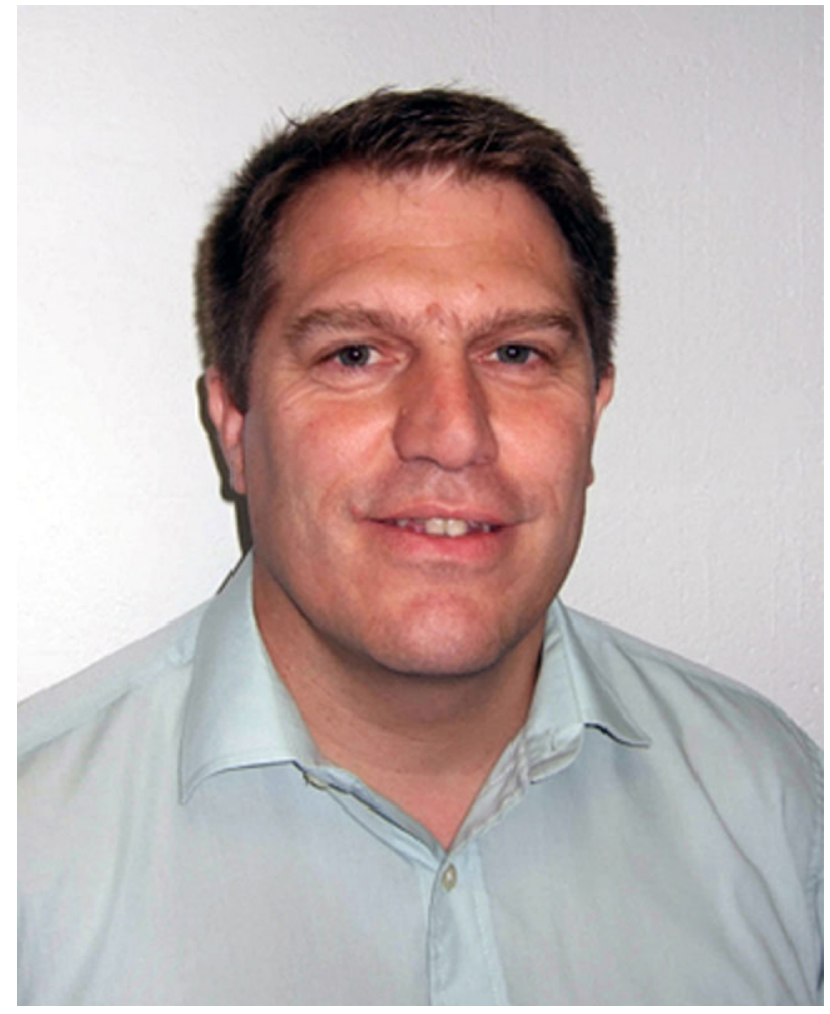

Bob Bateman has worked in the design and development of mass spectrometers since 1969, initially with AEI in Manchester, UK and then with VG, Micromass,

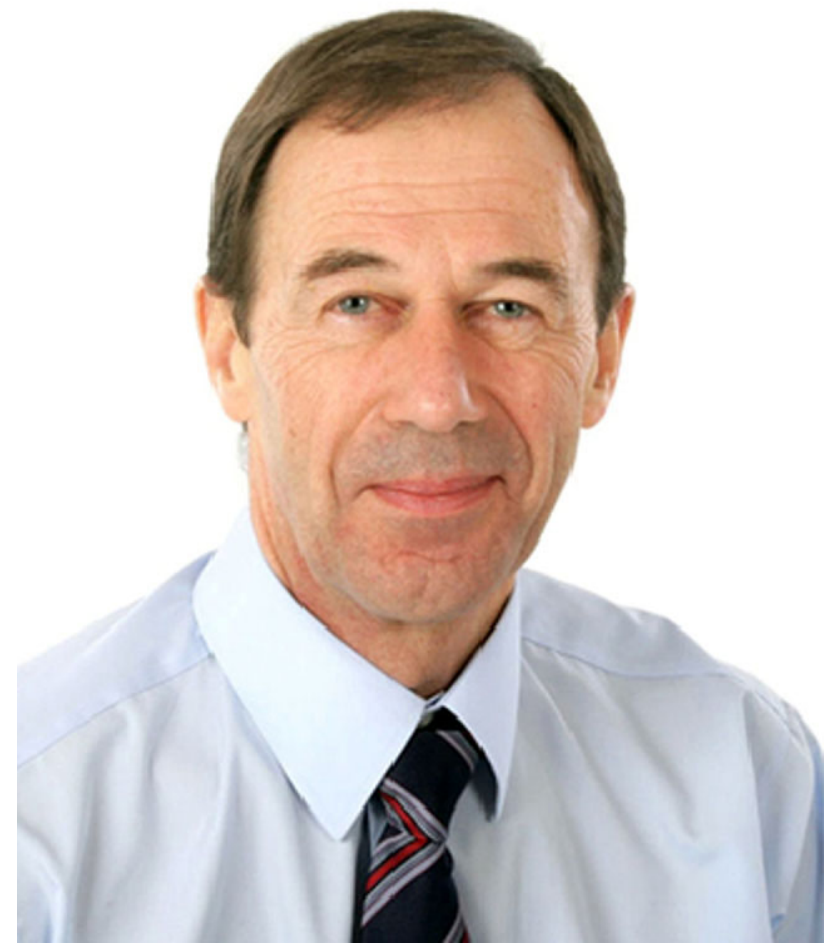


and Waters. He was responsible for the design of many commercial mass spectrometers and tandem mass spectrometers incorporating magnetic sector, quadrupole, and orthogonal acceleration time-of-flight mass analyzers. He was a director of VG Analytical and Micromass since 1985, managing Research and Development activities. Following the acquisition of Micromass by Waters Corporation, he became Vice President for MS Research until his retirement in 2008. He now works as a consultant with Waters. Bateman was awarded the BMSS Aston Medal in 2008.

The research reported in the paper results from a collaboration of academic and instrumentation company scientists, a promising and productive means of carrying out mass spectrometry based research and application.

If you want the full article, you may take advantage of an important feature of JASMS. Any article published more than one year ago may be downloaded free of charge even by non-members of ASMS and by interested persons who do not have access to a library subscription. In this case, I searched on Google Scholar for "alison e ashcroft JASMS 2007," and the first "hit" was a reference to the award-winning article. Clicking on the Google reference brings you to Science Direct and the article without charge. The feature is consistent with the journal and the society's policy to promote broad dissemination of articles published in the journal.

The editors of JASMS and the Board of Directors of ASMS hope you will nominate other deserving authors for the Ron Hites Award. The award is given annually for an exemplary paper published in the previous two volumes of JASMS. Papers may be nominated by anyone who reads JASMS. Nominations are accepted yearround, and should include a nomination letter not to exceed one page. Individuals may submit one nomination letter per year. Nominations should be submitted through the ASMS web site. The deadline for nomination for a given year is January 31 of that year and the award is made at the spring ASMS conference during the business meeting.

Congratulations to Alison and to her coauthors!

Michael L. Gross Editor in Chief Department of Chemistry, Washington University in St. Louis, St. Louis, Missouri, USA 